\title{
La decisión imposible en Schmitt y Derrida
}

\section{The Impossible Decision in Schmitt and Derrida}

\author{
Sebastián CHUN \\ Universidad de Buenos Aires \\ sebaschun@hotmail.com
}

Recibido: $15 / 05 / 2013$

Aceptado: 20/02/2014

\section{Resumen}

En Políticas de la amistad Derrida deconstruye la axiomática que Carl Schmitt despliega en El concepto de lo político, centrando su análisis en la decisión como instancia definitoria de la soberanía y señalando la imposibilidad de sostener una diferencia irreductible entre los planos ontológico y óntico, frontera fundamental para la formalización de lo político que realiza el jurista alemán. Así, gracias a esta mediación, podemos acercar la concepción schmittiana de la soberanía con las posiciones de aquellos autores llamados impolíticos. Por lo tanto, nuestra hipótesis consiste en considerar que la forma que tienen estos últimos de pensar la decisión soberana es fiel a Schmitt, lo cual se hará explícito gracias a la noción de "decisión imposible" que acuña Derrida y su propia reflexión sobre lo político

Palabras clave: Soberanía, decisión, deconstrucción, democracia por venir

\begin{abstract}
In The Politics of friendship Derrida deconstructs the axiomatic system that Carl Schmitt develops in The Concept of the Political by focusing his attention in the decision as the essential note of the sovereignty and arguing that the difference between the ontic and the ontological, fundamental frontier in Schmitt's formalization of the political, is impossible to sustain. This analysis allows us to put together the Schmittian conception of the sovereignty and the so called impolitical philosophers' one. The hypothesis of this text is that these aforementioned authors agree with Schmitt when they think about the sovereign decision. This will be clear when analysing the concept of the "impossible decision", as Derrida describes it and also his own political conception.
\end{abstract}

Keywords: Sovereignty, decision, deconstruction, democracy to come 
En el presente trabajo nos proponemos analizar los capítulos que Derrida dedica a Carl Schmitt en su libro Políticas de la amistad, buscando articular ambos pensamientos a partir del concepto de decisión y, gracias a esta mediación, también acercar la concepción schmittiana de la soberanía con las posiciones de aquellos autores llamados impolíticos ${ }^{1}$. En este sentido, vale recordar una vez más que para Schmitt "es soberano quien decide el estado de excepción", es decir, aquel que declara la suspensión de la ley, la puesta en suspenso de un orden determinado, por propia iniciativa, de manera original e incondicionada ${ }^{3}$. Por el lado de Bataille, a quien tomamos como representante de un pensamiento sobre lo político que él mismo inaugura ${ }^{4}$, encontramos que "la soberanía no es nada". En otras palabras, la decisión como instancia soberana no puede tener una finalidad o utilidad que determine y anule su absoluta espontaneidad. Por lo tanto, la soberanía no es algo determinable dentro del mundo regido por la lógica instrumental, no es una cosa que pueda reducirse al límite de lo útil. Nuestra hipótesis consiste en considerar que esta forma de pensar la decisión soberana es fiel a Schmitt, lo cual se hará explícito gracias a la lectura de El concepto de lo político que realiza Derrida y su propia reflexión sobre lo político ${ }^{6}$.

\footnotetext{
${ }^{1}$ Para la relación entre la teología política Schmittiana y el pensamiento del así llamado comunitarismo impolítico véase A. Galindo Hervás, La soberanía. De la teología política al comunitarismo impolítico, Murcia, Res publica, 2003; "Actualidad de la crítica de Schmitt al liberalismo", en Daímon. Revista de filosofía 27, Septiembre-Diciembre 2002, pp. 151-162; "Teología política <versus> comunitarismo impolítico", en Res publica. Revista de Filosofía Política 6, 2000, pp. 37-55.

${ }^{2}$ C. Schmitt, Teología política I, en Carl Schmitt, teólogo de la política, trad. A. Scherp, México, FCE, 2001, p. 23.

${ }^{3}$ Para un análisis de la decisión en Schmitt véase J. Dotti, “Teología política y excepción”, en Daímon. Revista de filosofía 13, Julio-Diciembre 1996, pp. 129-140; "Menage à trois sobre la decisión excepcional. Kierkegaard, Constant, Schmitt", en Deus mortalis 4, 2005, pp. 303-379; P. Peñalver Gómez, "Decisiones. Schmitt, Heidegger, Barth”, en Daímon. Revista de filosofía 13, Julio-Diciembre 1996, pp. 141-166.

${ }^{4}$ Desde ya que aquí dejamos de lado las importantes diferencias que existen entre las concepciones de lo político de Bataille y pensadores como Nancy, Blanchot, Agamben y Esposito. Véase A. Galindo Hervás, La soberanía. De la teología política al comunitarismo impolítico, cit.

${ }^{5}$ G. Bataille, Lo que entiendo por soberanía, trad. P. Sánchez Orozco y A. Campillo, Barcelona, Paidós, 1996, p. 113.

${ }^{6}$ Galindo Hervás articula ambas perspectivas sobre lo político y encuentra en la segunda una forma de evitar "la tentación teológico-política que le hace [a Schmitt] desear una unidad sin fisuras". A. Galindo Hervás, "Actualidad de la crítica de Schmitt al liberalismo", cit., p. 161. Por nuestra parte, siguiendo una lectura muy cercana a la anterior, intentaremos tender un puente entre Schmitt y el comunitarismo impolítico gracias a la interpretación derridiana.
} 


\section{Derrida lector de Schmitt}

El movimiento que realiza Derrida en Políticas de la amistad a la hora de abordar la concepción de lo político schmittiana nace en la crítica al concepto clásico de decisión que cierra el capítulo 3, pasando por los capítulos 4 y 5, donde Derrida deconstruye la sistemática de El concepto de lo político, para así llegar al capítulo 6 , en el cual señala el vínculo existente entre la dificultad de sostener la axiomática construida por Schmitt a partir de la diferencia entre amigo y enemigo y su Teoría del partisano ${ }^{7}$. Y esta impureza que encuentra Derrida en los conceptos schmittianos es el núcleo central de su hipótesis, según la cual el jurista alemán anticipa lo frágil de las fronteras que él mismo intenta proteger ${ }^{8}$. Esas fronteras permitirían evitar la caída en el mito y su violencia arrolladora para así buscar formas jurídicas que lo encausen, sin embargo, Derrida muestra cómo esa ontología de lo político se ve contaminada por su puesta en práctica, siendo estas raíces ónticas una fuente ineludible de impureza para aquellas distinciones conceptuales que Schmitt quisiera sostener.

Una vez expuesta nuestra hipótesis de lectura, analizaremos en detalle la deconstrucción derridiana de El concepto de lo político a partir de los cinco ejes que atraviesa.

1) El eje principal, que contaminará a todos los demás, es el de la distinción amigo-enemigo. Para Derrida, que lo político surja a partir de la figura del enemigo es el axioma fundamental en Schmitt ${ }^{9}$, fundamental tanto para su decisionismo como

\footnotetext{
${ }^{7}$ ¿Cómo definir la relación entre los pensamientos políticos de Schmitt y Derrida? ¿Crítica, deconstrucción, reescritura? Nuestra hipótesis de lectura intentará acercarlos, explicando así también el por qué de la ambigüedad con la que Derrida se refiere a la obra del jurista alemán. Por ejemplo cuando leemos que toda teoría de la decisión, incluso la Schmittiana, debe comprometerse en la aporía del quizá (J. Derrida, Políticas de la amistad, trad. P. Peñalver y F. Vidarte, Madrid, Trotta, 1998, p. 86); para luego encontrar que Derrida afirma que la decisión pasiva es rebelde a la concepción decisionista de la soberanía (cit., p. 87) y que finalmente señala que ha desplegado así la consecuencia clásica, ineluctable e imperturbable de un concepto clásico de la decisión (cit., p. 88).

8 "Ésta sería la escena según nuestra hipótesis: la lucidez y el miedo no sólo han impulsado a un vigilante aterrorizado e insomne a anticipar las tempestades y los seísmos que iban a trastornar el campo histórico, el espacio político, las fronteras de los conceptos y de los países, la axiomática del derecho europeo, los lazos entre lo telúrico y lo político, la técnica y la política, los media y la democracia parlamentaria, etc. De repente un tal "vigilante" habría sido más sensible que muchos otros a la fragilidad, a la precariedad "deconstruible" de las estructuras, de las fronteras y de los axiomas que él pretendía proteger, restaurar, 'conservar' a cualquier precio". J. Derrida, Políticas de la amistad, cit., p. 102.

${ }^{9}$ Derrida centra su análisis en el texto El concepto de lo político, por lo que dejará de lado la otra característica fundamental de la soberanía schmittiana: la representación.
} 
para su teoría de la excepción y la soberanía ${ }^{10}$. A la hora de establecer el criterio para determinar la presencia del enemigo, Schmitt señala que dicha distinción se apoya sobre el par público-privado. El enemigo siempre es público y nunca privado, es decir, su posibilidad está purificada de todo lo que pueda depender de lo individual, psicológico y subjetivo en general. La autonomía de la esfera política implica que cualquier otra distinción (religiosa, moral, estética, económica, etc.) puede alcanzar un grado de intensidad tal que llegue al caso extremo del agrupamiento con base en los conceptos amigo-enemigo ${ }^{11}$, pero una vez que esto sucede lo político domina toda la escena, desapareciendo cualquier otra instancia a partir de la cual se fundamentaría dicha enemistad ${ }^{12}$. Otro modo de abordar esta especificidad de lo político lo encontramos cuando Schmitt sostiene el carácter existencial de la enemistad política, única fuente de legitimación de la guerra, la cual no puede fundarse en normas éticas o jurídicas ${ }^{13}$. De esta manera, Schmitt evitaría la intromisión de un contenido empírico en la distinción formal entre amigos y enemigos, la cual ocasionaría un tipo de guerra más allá de las fronteras políticas, inhumana desde el momento en que se hace en nombre de un enemigo de la humanidad. Si se descalifica al enemigo bajo un perfil moral o de cualquier otro tipo, se está accediendo a una hostilidad absoluta que Schmitt se encarga de deslegitimar en repetidas ocasiones ${ }^{14}$. Y ésta es precisamente la contaminación ${ }^{15}$ que el pensador alemán necesita evitar y que Derrida postula como ineludible desde dos instancias.

En primer lugar, el filósofo franco-argelino afirma que Schmitt parece fundar la distinción entre privado y público en la etimología, a partir de los pares hostis/inimicus y polémios/ekhthrós ${ }^{16}$. Y es allí donde Schmitt recurre a Platón para sostener esa posibilidad de purificar el ámbito de lo público, mientras que Derrida demostrará cómo en el texto platónico dicha distinción se construye sobre un discurso sobre la phýsis que regirá el espacio del nomos ${ }^{17}$. Si bien no entraremos en detalle sobre la ar-

\footnotetext{
${ }^{10} \mathrm{~J}$. Derrida, Políticas de la amistad, cit., p. 103.

${ }^{11}$ C. Schmitt, El concepto de lo político, en Carl Schmitt, teólogo de la política, trad. E. Molina y Vedia y R. Crisafio, México, FCE, 2001,p. 180.

${ }^{12}$ Ibidem, p. 187.

${ }^{13}$ Ibidem, p. 196.

${ }^{14}$ Ibidem, pp. 186, 201.

15 "Una guerra tiene su sentido en el hecho de ser librada no por ideales o normas jurídicas sino contra un enemigo real. Todas las contaminaciones (Trübungen) de esta categoría de amigo y enemigo se explican teniendo en cuenta su mezcla (Vermengung) con alguna abstracción o norma". Ibidem, p. 197.

${ }^{16}$ Ibidem, p. 179.

17 "Todo parece decidirse allí donde la decisión no tiene lugar, precisamente en ese lugar donde ella no tiene lugar en tanto decisión, allí donde habrá sido arrastrada, allí donde habrá sido arrebatada en lo que siembre habrá tenido ya lugar: en el nacimiento o, mejor dicho, en la víspera del naci-
} 
gumentación derridiana, el problema en Schmitt reside en su presentación de un pensamiento que busca sus pilares en el ámbito biológico-natural como fundamento de una distinción formal entre lo público y lo privado ${ }^{18}$. Con el hostis/polémios es posible la guerra (pólemos), pero al interior sólo es posible la discordia (stásis) con el inimicus/ekhthrós. Y precisamente en la imposibilidad del enemigo interior radica el punto neurálgico de la conceptualización schmittiana. Si bien es posible la guerra civil, la misma implica como condición de posibilidad la disolución de la unidad política ${ }^{19}$. El inimicus/ekhthrós siempre es interior aunque no necesariamente sea un enemigo privado, es decir, es un amigo con quien puedo tener una stásis. El hostis/polémios es únicamente exterior a la unidad política y la enemistad que nos une debe ser pública, para así dar lugar a la posibilidad del pólemos. Sin embargo, la imposibilidad de sostener esta distinción formal conducirá para Derrida a la superpolitización de la Teoría del partisano, que convierte al amigo/hermano en el enemigo absoluto $^{20}$.

En segundo lugar, Derrida muestra cómo la axiomática schmittiana es ajena a toda puesta en práctica posible. Reproduciendo la clásica aporía de la ética kantiana ${ }^{21}$, para que ese criterio que define lo político se mantenga formal debe estar libre de toda empiria ${ }^{22}$. Aunque de cualquier otra esfera se pueda saltar hacia lo político, este paso siempre es cualitativo, en el sentido de que presupone un vaciamiento del concepto de enemigo para volverlo meramente formal-existencial. Para Schmitt no puede haber contaminación si se quiere evitar la xenofobia y el establecimiento de un enemigo de la humanidad. Leemos por lo tanto en Derrida,

"He aquí una experiencia del amigo/enemigo totalmente pura, en su esencia política, de todo afecto, al menos de todo afecto personal, suponiendo que haya algún otro. Si el enemigo es el extranjero, la guerra que le haré debería mantenerse, en lo esencial,

miento, en esa necesidad que obliga (anagkázei), en el nacimiento, en el buen nacimiento, en la eugeneia, a buscar una igualdad ante la ley que sea conforme a la igualdad en el nacimiento". J. Derrida, Políticas de la amistad, cit., p. 121.

${ }^{18}$ Ibidem, pp. 110-129.

${ }^{19}$ C. Schmitt, El concepto de lo político, cit., p. 182.

20 "Sólo hay hostilidad absoluta para un hermano". J. Derrida, Políticas de la amistad, cit., p. 171.

${ }^{21}$ Kant se pregunta cómo dejar de lado el imperio del ego a la hora de actuar. Por lo tanto, si buscamos una acción moral debemos abandonar el ámbito regido por lo particular (lo empírico, las inclinaciones, lo patológico) para así elevarnos hacia la universalidad (lo formal, lo racional). Signo de la dificultad que plantea este pasaje es la imposibilidad de ejemplificar su ética con alguna conducta determinada. I. Kant, Fundamentación de la metafísica de las costumbres, trad. M. G. Morente, México, Porrúa, 1995.

${ }^{22}$ Derrida habla incluso de un procedimiento fenomenológico en Schmitt. "De acuerdo con lo que parece al menos una reducción eidética, hay que poner entre paréntesis todo hecho y toda región que no se anuncien como políticos". J. Derrida, Políticas de la amistad, cit., p. 106. 
sin odio, sin xenofobia intrínseca. Y lo político comenzará gracias a esta purificación. Gracias al cálculo de esta purificación conceptual”23.

Así como en Kant no podemos encontrar un ejemplo de acción buena, desde el momento en que lo empírico-subjetivo siempre puede entrometerse en nuestra decisión supuestamente formal, lo mismo sucede en $\mathrm{Schmitt}^{24}$. ¿Cómo asegurarnos de la pureza esencial del enemigo político a la hora de pensar en una puesta en práctica de la guerra existencial? Problema más que grave desde el momento en que Schmitt no querría distinguir el plano ontológico del óntico, reconociendo una impureza fundamental en su propia conceptualización, con las consecuencias nefastas que él mismo diagnostica para dicha sobredeterminación de la esfera política.

2) Ya en el capítulo 3 de Políticas de la amistad Derrida anticipa lo que será su crítica a la decisión tal como la concibe Schmitt, según nuestra hipótesis gracias a que hereda su propuesta ${ }^{25}$. Si bien ya en Teología política I encontramos la figura del soberano ligada directamente a la posibilidad de la decisión excepcional, en El concepto de lo político vuelve a aparecer en toda su pureza ontológica,

"El real agrupamiento amigo-enemigo es por su naturaleza tan fuerte y exclusivo que la contraposición no política, en el mismo momento en que causa este reagrupamiento, niega sus motivos y criterios hasta entonces "puramente" religiosos, [económicos] o culturales ("rein" religiösen, "rein" wirtshchaftlichen, "rein" kulturellen), y es sometida a los condicionamientos y a las consecuencias totalmente nuevas, peculiares y, desde la perspectiva de aquel punto de partida "puramente" religioso, económico o de otro tipo ( "rein" religiösen oder "rein" wirtshchaftlichen und anderen "reinen" Aus-

\footnotetext{
${ }^{23}$ Ibidem, p. 107.

24 "Conclusión práctica: en la práctica, dicho de otro modo, en esa práctica política que es la historia, esa diferencia entre los litigios no tiene lugar nunca. No se la encuentra nunca. Nunca concretamente. Por consiguiente, permanece inencontrable la pureza del pólemos o del enemigo mediante la que Schmitt pretende definir lo político. El concepto de lo político corresponde, sin duda, como concepto, a lo que el discurso ideal puede querer enunciar como más riguroso acerca de la idealidad de lo político. Pero ninguna política ha sido adecuada jamás a su concepto". J. Derrida, Políticas de la amistad, cit., p. 134.

25 "Una herencia nunca se re-úne, no es nunca una consigo misma. Su presunta unidad, si existe, sólo puede consistir en la inyunción de reafirmar eligiendo. Es preciso quiere decir es preciso filtrar, cribar, criticar, hay que escoger entre los varios posibles que habitan la misma inyunción. Y habitan contradictoriamente en torno a un secreto. Si la legibilidad de un legado fuera dada, natural, transparente, unívoca, si no apelara y al mismo tiempo desafiara a la interpretación, aquél nunca podría ser heredado. Se estaría afectado por él como por una causa -natural o genética-. Se hereda siempre de un secreto -que dice: "Léeme. ¿Serás capaz de ello?"-”. J. Derrida, Espectros de Marx, trad. J. M. Alarcón y C. de Peretti, Madrid, Trotta, 1995, p. 30.
} 
gangspunkt), a menudo muy inconsecuentes e "irracionales", de la situación política. En todo caso es siempre, por eso, el reagrupamiento decisivo (maßgebende), y como consecuencia de ello la unidad política, todas las veces que existe, es la unidad decisiva (maßgebende) y "soberana" en el sentido de que la decisión (Entscheidung) sobre el caso decisivo (maßgebenden Fall), aun cuando éste sea el caso de excepción, por necesidad lógica debe corresponderle a ella"26.

La decisión sobre el caso decisivo, para mantenerse formal, pura, sin contaminación empírica, no debe perseguir nada más que a sí misma (nuevamente el gesto kantiano). No sólo escapa a las normas establecidas, las cuales resultan inoperantes ante el surgimiento de la excepcionalidad misma, sino también a cualquier intromisión de otra esfera en el campo específicamente político.

A pesar de esto, Schmitt señala que el soberano tiene como fin la reinstauración del orden. Por lo tanto, este momento de apertura hacia lo otro, hacia lo más allá de la norma, se vuelve un riesgo necesario para lograr el cierre del universal que rige el orden dado $^{27}$. Ante el peligro de disolución de la normalidad establecida, que se manifiesta con la aparición de lo otro, lo heterónomo, el caso excepcional, el soberano decide hacer visible eso otro, nombrándolo y a su vez sentenciando su exclusión del orden, para así intentar fagocitarlo o borrarlo de la escena pública. El otro trae consigo la posibilidad de otra normalidad, de otro modo de vida, poniendo así en riesgo el estado de cosas vigente, que a ese otro lo dejaba en lo oculto, más allá de todo horizonte de posibilidad. Lo heterogéneo es lo imposible, lo impensado, y por ello debe volver a su morada de ruinas. Parece existir, entonces, una contradicción entre esta finalidad de autoconservación y la supuesta originalidad absoluta de la decisión. Para Schmitt "en términos normativos, la decisión surge de la nada" 28. Luego, la anterioridad de lo heterónomo, de lo a-normal, parece oponerse a la espontaneidad del soberano divino. La decisión, para ser tal, debe producir acontecimiento, por lo tanto escapa al cálculo, proyecto o voluntad del sujeto ${ }^{29}$. La decisión es la del caso excepcional (maßgebenden Fall) y no la prerrogativa soberana (Entscheidung). El deus mortalis ya no decide quién es ese otro, sino que simula darle una luz, cobijarlo bajo su campo de atracción y luego declararlo fuera del mismo; cuando en realidad sólo asumiría este riesgo para volver a lo normal, haciendo de lo invisible el hogar de lo heterónomo. De este modo, la decisión soberana no sería la iniciativa absoluta de una voluntad autosuficiente, sino que se puede pensar como el último recurso de aquél que ya no domina la distribución de espacios y roles, a quien

\footnotetext{
${ }^{26}$ C. Schmitt, El concepto de lo político, cit., p. 187 (traducción levemente modificada).

${ }^{27}$ Ibidem, p. 27.

${ }^{28}$ Ibidem, p. 40.

${ }^{29}$ J. Derrida, Políticas de la amistad, cit., p. 87.
} 
se le ha infiltrado un huésped indeseable que contamina la atmósfera de su reinado. Y aquí podemos acercarnos a la concepción de la soberanía en Bataille. Éste también parece tomarse en serio la pureza de la decisión schmittiana, reconociendo que la misma no debe estar regida por finalidad alguna. Desde ya que la cuestión aquí es dónde se pone el acento. Schmitt es un jurista que piensa en la necesidad de la construcción de un orden, mientras que desde nuestra perspectiva la concepción de Bataille y Derrida, salvando las infinitas diferencias, pondrían el acento en el momento deconstructivo. La decisión, señala Derrida, hace excepción del sujeto ${ }^{30}$, y así nos invita a pensar la (im)posibilidad de una decisión pasiva, es decir, una heteronomía que a su vez reconozca la responsabilidad del "sujeto" que la encarna. La decisión siempre viene del otro, escapando a mi horizonte de posibilidad determinado a partir de mi presente. Entonces la decisión está siempre por venir. Esto no significa que como concepto político no tenga relevancia alguna, sino todo lo contrario. La decisión, tal como la concibe el propio Schmitt, debe ser una llamada constante a la deconstrucción de cualquier instancia que se apropie de ella. No hay soberano ni decisión, sino siempre ficciones que deben ser deconstruidas inmediatamente desde el momento en que se apropian de esos nombres. Así se escaparía a cualquier posición totalitaria, desde el momento en que toda decisión se reconoce infiel a sí misma ${ }^{31}$. Desde ya que esto no significa que podamos clasificar decisiones más o menos fieles a su esencia, sino que toda decisión siempre traicionará su propia especificidad. Como ya mencionamos, Schmitt no puede reconocer esto, ya que su interés está puesto en la construcción de un orden, por lo tanto debe aceptar la posibilidad de una pura impureza o una impura pureza, es decir, de la realización efectiva de lo que plantea en términos ontológicos ${ }^{32}$. En otras palabras, si Derrida hace un llamado a la deconstrucción constante de cualquier institución política es por su fidelidad a la decisión soberana como instancia determinante de lo político, mientras que Schmitt inaugura esta posibilidad pero la deja de lado desde el momento en que necesita encontrar en la práctica una decisión tal como él mismo la postula, para así fundamentar un orden determinado. Ambos pensadores reconocen el abismo detrás de la política, pero uno decide profundizarlo y evidenciarlo, mientras que el otro busca clausurarlo a partir de la figura soberana. Desde ya que aquí está en juego la concepción de Schmitt sobre la imposibilidad de escapar al binomio orden $/ \operatorname{caos}^{33}$, mientras que Derrida querría pensar en un "entre" que sin ser

\footnotetext{
${ }^{30}$ Ibidem, p. 87.

${ }^{31}$ Nuevamente mencionamos la cercanía con la lectura de Galindo Hervás, cuando señala que la forma de sostener la crítica Schmittiana al liberalismo sin suscribir a la tentación teológico política de construir una unidad sin fisuras es mantener la consciencia de la contingencia absoluta que definirá a tales unidades. A. Galindo Hervás, "Actualidad de la crítica de Schmitt al liberalismo", cit.p. 161.

${ }^{32}$ J. Derrida, Políticas de la amistad, cit., p. 136.
} 
la instauración de un orden total y monolítico tampoco recaiga en el liberalismo o el peligro de lo meramente caótico ${ }^{34}$.

3) En tercer lugar Derrida analiza y saca provecho del entramado conceptual schmittiano entre posibilidad, eventualidad y efectividad. Leemos en Schmitt:

"Aquí no se trata de ficciones y de normatividades sino sólo de la plausibilidad (seinsmäßige Wirklichkeit) y de la posibilidad real (reale Möglichkeit) de nuestra distinción. [...] Enemigo no es el competidor o el adversario en general. Enemigo no es siquiera el adversario privado que nos odia debido a sentimientos de antipatía. Enemigo es sólo un conjunto de hombres que combate, al menos virtualmente (wenigstens eventuell), o sea sobre una posibilidad real (realen Möglichkeit), y que se contrapone a otro agrupamiento humano del mismo género" 35 .

La distinción política, aquella que enfrenta a los amigos que conforman una unidad política con los enemigos de la misma, no es una distinción efectiva, real, actual, sino todo lo contrario. Lo que determina su eficacia es precisamente su carácter plausible, su posibilidad real, su virtualidad. Por esta razón Schmitt puede argumentar que el caso de excepción es aquel capaz de revelar la esencia de las cosas, precisamente porque su carácter de meramente posible lo vuelve determinante de la tensión específicamente política que adquiere la vida del hombre ${ }^{36}$. La guerra, la posibilidad de dar muerte al otro, cuanto más excepcional, rara, improbable, más efectivamente pesa sobre la decisión ${ }^{37}$. Y de aquí Derrida extraerá su argumento para deconstruir este punto de la posición schmittiana. Si la excepción hace la regla, cuanto más improbable sea una situación decisiva más intensa y reveladora será, es decir, cuanto mayor sea la despolitización mayor será la politización ${ }^{38}$. Recordando la crítica de Schmitt al liberalismo despolitizador, éste sería la máxima expresión de la política por su misma anulación del enemigo. Y esta paradoja surge también a partir de la indistinción por parte de Schmitt entre un discurso metafísico-ontológico sobre la decisión y la imposibilidad de su aplicación efectiva, ya que el jurista alemán necesita también en este punto saltar de lo virtual a lo actual, no pudiendo reconocer las consecuencias de dicho salto para su misma conceptualización.

\footnotetext{
33 "Si la metafísica se constituye a partir de la pregunta ¿por qué el ser y no la nada?, la teología política lo hace a partir de ¿por qué el orden y no el caos? Su respuesta es: por la decisión excepcional sobre lo excepcional”. J. Dotti, “Teología política y excepción”, cit., p. 129.

${ }^{34}$ Volveremos a esta cuestión en la parte b del presente trabajo.

${ }^{35}$ C. Schmitt, El concepto de lo político, cit., p. 179.

${ }^{36}$ Ibidem, p. 185.

${ }^{37}$ J. Derrida, Políticas de la amistad, cit., p. 150.

${ }^{38}$ Ibidem, p. 152.
} 
4) El cuarto eje nace en la afirmación de Schmitt según la cual todos los conceptos, expresiones y términos políticos son polémicos, desde el momento en que su sentido está proporcionalmente ligado a una conflictualidad concreta ${ }^{39}$. Y es así como debemos comprender el mismo concepto de lo "político" schmittiano, en tanto medio de lucha contra la avanzada despolitizadora liberal. El sentido de dicho concepto está construido a partir de la polémica que encarna Schmitt contra su enemigo declarado, y es justamente por esto que ese criterio formal para delimitar lo propio de una esfera de acción ya está contaminado por su puesta en práctica. La conceptualización schmittiana está vinculada estrechamente con un campo de batalla concreto que afecta necesariamente la pureza "ontológica" que pretendiera para su teoría, sin la cual correría el riesgo de caer en lo peor de la guerra en nombre de la humanidad a partir de la postulación de un valor determinado como universal ${ }^{40}$. El problema, lo repetimos, no es esta deconstrucción en acto sino la confusión que conlleva de dos ámbitos heterogéneos: el ontológico y el práctico. Esto implica la aceptación de un Estado absoluto que podría encarnar la verdad de ese criterio formal, pero así como en Kant no se podía establecer cuál era un acto justo, tampoco se podría establecer dónde se encontraría la decisión soberana garante de la existencia divina de ese Estado.

5) En quinto lugar, la interrelación entre Estado y política es deudora de esta contaminación también. Si bien Schmitt abre El concepto de lo político afirmando que la política excede lo estatal ${ }^{41}$, una vez que confunde el ámbito formal y el práctico esta separación pierde su vigencia. Desde ya que lo político funda lo estatal, ya que es la condición de posibilidad de la conformación de una unidad decisiva. Pero si bien para Schmitt la política encuentra su forma de expresión adecuada en el Estado, finalmente es éste el único sujeto capaz de decisión alguna ${ }^{42}$. Para Derrida, el pasaje entre El concepto de lo político y Teoría del partisano se articulará a partir de este privilegio de lo estatal y, por lo tanto, de la figura del amigo o el enemigo como ciudadano ${ }^{43}$.

\footnotetext{
${ }^{39}$ C. Schmitt, El concepto de lo político, cit., p. 181.

40 "Tan sólo se tratará, como hemos anunciado, del uso polémico de este concepto de lo político [...] Esa necesidad no puede dejar intacto un presunto discurso teórico sobre el tema, un metadiscurso, un discurso meta-polémico o meta-político, un discurso polemo-lógico o polito-lógico. ¿Se dirá que el discurso Schmittiano pretende esa teoreticidad pura? Desde ciertas perspectivas, sí, eso creemos, y ése es en buena medida el interés de su proyecto". J. Derrida, Políticas de la amistad, cit., p. 137.

${ }^{41}$ C. Schmitt, El concepto de lo político, cit., p. 171.

42 " [...] el Estado es una situación, definida de una manera particular, de un pueblo, más precisamente la situación que sirve de criterio en el caso decisivo, y constituye por ello el status exclusivo frente a los muchos posibles status individuales y colectivos". Ibidem, p. 171.

${ }^{43}$ J. Derrida, Políticas de la amistad, cit., p. 141.
} 


\section{Política por venir}

Hay en Derrida una relación estrecha entre el porvenir y el acontecimiento, desde el momento en que ambos comparten su irreductibilidad al cálculo a partir de las condiciones actuales. En otras palabras, son su imprevisibilidad, su más allá del horizonte presente, su suspensión de todo saber, los que garantizan su (im)posibilidad. Lo único que está por venir es el acontecimiento, si lo hay ${ }^{44}$, cuya condición de posibilidad es la transgresión de la mera repetición de lo mismo, su irreductibilidad a la racionalidad instrumental y a la aplicación de un programa, es decir, la fidelidad al llamado de la deconstrucción. Ahora bien, la pregunta que podemos hacernos en este punto es cómo pensar el acontecimiento, cómo volver la razón sobre esto que da a pensar. Derrida responde,

"Pero el pensamiento del 'quizá' involucra quizá el único pensamiento posible del acontecimiento. De la amistad por venir y de la amistad para el porvenir. Pues para amar la amistad no basta con saber llevar al otro en el duelo, hay que amar el porvenir. Y no hay categoría más justa para el porvenir que la del 'quizá'. Tal pensamiento conjuga la amistad, el porvenir y el quizá para abrirse a la venida de lo que viene, es decir, necesariamente bajo el régimen de un posible cuya posibilitación debe triunfar sobre lo imposible. Pues un posible que sería solamente posible (no imposible), un posible seguramente y ciertamente posible, de antemano accesible, sería un mal posible, un posible sin porvenir, un posible ya dejado de lado, cabe decir, afianzado en la vida. Sería un programa o una causalidad, un desarrollo, un desplegarse sin acontecimiento. La posibilitación de ese posible imposible debe permanecer a la vez tan indecidible y en consecuencia tan decisivo como el porvenir mismo" ${ }^{45}$.

El pensamiento del quizá entonces piensa aquello que escapa a nuestro pensamiento, es decir, a nuestro lenguaje. Si no podemos dejar de traicionar el porvenir cada vez que hablamos sobre él, esto es porque el porvenir nunca llega, sino que siempre está por venir. Otra política, otra democracia, no pueden renunciar al contenido heredado de esos conceptos. Sin embargo, si no hay una herencia determinada, eso que se hereda es siempre la apertura al acontecimiento, a aquello inesperado que irrumpe de manera novedosa sobre el orden constituido, y que quizá, pero sólo quizá, pueda suceder. Y aquí Derrida señala la prueba que debe hacer todo porvenir, la aporía del quizá. Por un lado, el quizá abre un posible absolutamente indeterminado, que permite así el acontecimiento y la decisión. Por el otro, toda decisión interrumpe su condición de posibilidad, el quizá mismo. En otras palabras, la decisión (que siem-

\footnotetext{
44 “Lo que hay, si es que lo hay, no es necesariamente. Eso quizá no existe ni se presente jamás, y sin embargo lo hay, puede que haya". Ibidem, p. 58.

${ }^{45}$ Ibidem, p. 46.
} 
pre es de otro y nunca una puesta en acto de una voluntad soberana) y el surgir del acontecimiento clausuran el horizonte abierto a la llegada de lo otro ${ }^{46}$. En el preciso instante en que del fondo de indeterminación acontece lo imposible, eso ya queda reducido al ámbito de lo posible. La justicia, el don, el perdón, si los hay, siempre serán fugaces, imponiéndonos un deber fundamental, el de deconstruir todas las instancias que se realizan en sus nombres.

Por otro lado, Derrida señala la aporía del acontecimiento, que se superpone a la antes analizada. Según esta segunda aporía, la decisión produce acontecimiento, es decir, siempre es una decisión que se toma sobre un suelo de indecidiblidad absoluta $^{47}$. Por lo tanto, no hay un sujeto que tome una decisión, si comprendemos por tal al individuo claramente determinado, autoconsciente y capaz de calcular las causas y efectos de su decisión. Sin embargo, Derrida señala que la decisión neutraliza a su vez esa indeterminación absoluta, ya que siempre tiene un efecto de subjetividad inherente a ella misma.

"Sin duda la subjetividad de un sujeto, ya, no decide nunca sobre nada: su identidad consigo y su permanencia calculable hacen de toda decisión un accidente que deja al sujeto indiferente. Una teoría del sujeto es incapaz de dar cuenta de la menor decisión [...] Pero si nada sucede jamás a un sujeto, nada que merezca el nombre de acontecimiento, el esquema de la decisión tiende regularmente, al menos en su acepción común y hegemónica (la que parece seguir dominando el decisionismo schmittiano, su teoría de la excepción y de la soberanía), a implicar la instancia del sujeto, de un sujeto clásico, libre y voluntario, y así de un sujeto al que nada sucede, ni siquiera el acontecimiento singular del que cree, por ejemplo en situación de excepción, que toma y que guarda la iniciativa. [...] ¿Habría que mostrarse hospitalario para lo imposible mismo, a saber, lo que el buen sentido de toda filosofía no puede sino excluir como la locura o el sin-sentido, a saber, una decisión pasiva, una decisión originariamente afectada? [...] la decisión: ésta debe interrumpir, marca un comienzo absoluto. Significa, pues, lo otro en mí, que decide y desgarra. La decisión pasiva, condición del acontecimiento, es siempre en mí, estructuralmente, otra decisión, una

\footnotetext{
${ }^{46}$ Ibidem, p. 86.

${ }^{47}$ En Fuerza de ley Derrida da tres ejemplos de aporías íntimamente ligadas a las aquí expuestas. I. La epokhé de la regla. Según ésta, la decisión del justo, para ser tal, deber ser del orden de lo calculable, es decir, debe seguir una regla. Pero para ser justa, el juez debe asumir esa regla en un acto de interpretación reinstaurador. II. La obsesión (hantise) de lo indecidible. Aquí Derrida afirma que la decisión debe pasar por la prueba de lo indecidible. Una vez pasada esa prueba, esa decisión deja de ser justa, es decir, cae nuevamente bajo la regla o norma instituida. III. La urgencia que obstruye el horizonte del saber. La decisión siempre marca una interrupción del saber y la deliberación. Sin embargo, dicho saber debe necesariamente preceder a toda decisión. J. Derrida, Fuerza de ley. El "Fundamento místico de la autoridad", trad. A. Barberá y P. Peñalver Gómez, Madrid, Tecnos, 1997, pp. 52-62.
} 
decisión desgarradora como decisión del otro. Del otro absoluto en mí, del otro como lo absoluto que decide de mí en mí. [...] Responsable de mí ante el otro, soy en primer lugar y también responsable del otro ante el otro [...] esta heteronomía no contradice a la autonomía, abre ésta a ella misma, representa el latido de su corazón. Otorga la decisión al don, si lo hay, como don del otro"48.

El sujeto clásico, libre y voluntario, responde al principio de calculabilidad propio de todo lo presente, lo posible, lo estable, lo idéntico a sí. Por ello, no es posible hablar de una decisión de ese sujeto en tanto ésta es siempre el venir del acontecimiento, lo que irrumpe, lo no-calculable e in-anticipable. Por otro lado, toda decisión tiene un efecto de subjetividad necesario, es decir, no puede ir más allá de ese sujeto al que se le impone desde otro lugar. Entonces, una decisión, si la hay, viene de lo otro en mí, ese otro que decide más allá de mí mismo. Sin embargo, no por esto dejo de ser responsable, infinitamente responsable, de esa decisión del otro ${ }^{49}$. Y aquí reside el efecto de subjetividad necesario para pensar en otra política: el sujeto de la democracia por venir sería uno cuya identidad estaría conformada por la respuesta y la responsabilidad ante la decisión del otro.

Lo que finalmente se explicita aquí es el papel que tiene en el pensamiento derridiano en general la aporía como instancia de apertura del acontecimiento ${ }^{50}$. Para que el porvenir tenga lugar, es necesaria la instancia de indeterminación propia de lo aporético, es decir, de aquello que no nos permite trazar de antemano la senda segura que debe seguir nuestra decisión (lo cual la anularía en cuanto tal). Cuando nos vemos atravesados por dos deberes irrenunciables, lo que Derrida llama double bind, precisamente en ese momento lo otro que rompe con la mera repetición de lo mismo es posible. En Fuerza de ley Derrida sostiene incluso que la justicia sería la experiencia de la aporía, es decir, de aquello de lo que no se puede tener experiencia. La justicia sería entonces la única experiencia posible de lo imposible.

"El derecho es el elemento del cálculo, y es justo que haya derecho; la justicia es incalculable, exige que se calcule con lo incalculable; y las experiencias aporéticas son experiencias tan improbables como necesarias de la justicia, es decir, momentos en que la decisión entre lo justo y lo injusto no está jamás asegurada por una regla"51.

\footnotetext{
48 J. Derrida, Políticas de la amistad, cit., pp. 86-87.

49 "Una decisión es inconsciente en suma, por insensato que esto parezca, comporta el inconciente y sigue siendo sin embargo responsable" Ibidem, p. 88.

50 “[...] la aporía es el lugar mismo en el cual ha de encontrarse la fuerza política de la deconstrucción.” R. Beardsworth, Derrida y lo político, trad. L. Lassaque, Bs. As., Prometeo, 2008, p. 19. ${ }^{51}$ J. Derrida, Fuerza de ley. El "Fundamento místico de la autoridad”, cit., p. 39.
} 
La aporía deja entonces de ser un mero callejón sin salida, y el espacio abierto por lo indecidible se hace transitable. Ya no caemos condenados bajo el yugo del quietismo, sino que reconocemos que toda instancia de suspensión del cálculo y la causalidad se vuelve condición de posibilidad de la justicia, el respeto absoluto hacia el otro, es decir, la democracia por venir.

En el seminario recientemente traducido al castellano titulado La bestia y el soberano Derrida recuerda su lectura de Schmitt y señala lo siguiente:

“[...] en Políticas de la amistad, lo que busco sería pues una deconstrucción lenta y diferenciada [...] del concepto dominante, clásico, de soberanía del Estado-nación (el que sirve de referencia a Schmitt) sin desembocar en una des-politización, sino en otra politización, en una re-politización que no caiga en los mismo carriles de la "ficción deshonesta", sin desembocar pues en una des-politización sino en otra politización, en una re-politización y, por lo tanto, en otro concepto de lo político. Que esto resulte más que difícil es algo demasiado evidente y por eso trabajamos, trabajamos en ello y nos dejamos trabajar por eso" 52 .

A partir de este pasaje comprendemos que cuando Derrida habla de "democracia por venir" está realizando un llamado a la deconstrucción de cualquier instancia política que pretenda apropiarse del nombre democracia. Del mismo modo, su "decisión por venir" implica la deconstrucción de toda institución decisiva efectiva. En este sentido, pensar otro modo de lo político no conduce a una inactividad o pasividad necesarias, sino que motoriza una constante profundización de la deconstrucción que ya está en marcha ${ }^{53}$.

Por otro lado, no es justo tampoco criticar a Derrida por caer en las redes del liberalismo, ya que su concepción de lo político no deja de suscribir a la crítica schmittiana contra el mismo, y en este sentido hereda su concepto de decisión. Sin embargo, Derrida no adhiere a la axiomática schmittiana en su totalidad, rompiendo así con la dicotomía Estado/liberalismo ${ }^{54}$, y todo su esfuerzo estará dedicado a poder pensar

\footnotetext{
52 J. Derrida, Seminario: la bestia y el soberano. Volumen I (2001-2002), trad. C. de Peretti y D. Rocha, Bs. As., Manantial, 2010, p. 103.

${ }^{53}$ Derrida reconoce que no hay un más allá de la historia de la metafísica. Por lo tanto, la deconstrucción se muestra como "un modo de habitar las estructuras metafísicas para llevarlas hasta su límite: solicitación (en el sentido etimológico de "hacer temblar") que permitirá que dichas estructuras muestren sus "fisuras")". M. B. Cragnolini, "Derrida: deconstrucción y pensar en las <fisuras>", en Derrida, un pensador del resto, Bs. As., La cebra, 2007, p. 21.

${ }^{54}$ Para Derrida la axiomática Schmittiana es reemplazada por la axiomática imposible de pensamientos como el de Bataille, Blanchot y Nancy, síntoma de una transformación en curso. Tal vez no sea casual que Derrida comience el capítulo 4 con esta referencia. J. Derrida, Políticas de la amistad, cit., pp. 99-101.
} 
una política, un modo de lo político, que vaya más allá de dicha pareja ${ }^{55}$.

La deconstrucción, si la hay, es una labor inconclusa, compañera fiel y perseverante de esa perfectibilidad infinita propia de la política y del derecho. Y esta política del porvenir que es la deconstrucción nos transmite la urgente necesidad de transitar las fisuras de toda institucionalización de lo político en búsqueda de la invención de lo otro por venir. Si en Derrida no hay un contenido determinado que conforme un programa político, esto no significa que no haya una tarea inmediata. Que los deberes a los que nos llama la democracia por venir sean instancias aporéticas que no prescriben cómo seguir responde a una justicia y respeto absolutos por toda alteridad, aquí y ahora. Y esta idea de urgencia la encontramos una y otra vez en los textos derridianaos. Por ejemplo, cuando se pregunta por las condiciones de posibilidad de que hoy en día expresiones como comunidad sin comunidad tengan sentido ${ }^{56}$, o cuando anuncia las señales de una nueva Internacional ${ }^{57}$, o también cuando menciona justamente que nuestra tarea es la intensificación máxima de una transformación en curso $^{58}$. Por lo tanto, la deconstrucción, como puesta en práctica de una política por venir, responde a una demanda actual, histórica ${ }^{59}$, que nos convoca a responder al llamado de todos los otros que buscan visibilizarse y tener voz. A su vez, se instala allí donde la lógica hobbesiana del "hombre lobo del hombre" se pone en cuestión, desde que una promesa, un don, el perdón y la propia democracia se ensayan día a día. ¿Cuál es la condición de posibilidad de estos simulacros? Precisamente esa otra relación imposible con el otro, ya actualizada en la promesa que acompaña a toda alo-

\footnotetext{
55 “A través de esta despolitización, que concerniría sólo al concepto fundamental y dominante de lo político, a través de esta desconstrucción genealógica de lo político (y, en ello, de lo democrático), se intentaría pensar, interpretar, poner en acción, otra política, otra democracia. [...] Se trataría también de una desconstrucción del esquema genealógico, de una desconstrucción paradójica, de una desconstrucción a la vez genealógica y a-genealógica de lo genealógico". Ibidem, p. 127.

${ }^{56}$ Ibidem, p. 62.

${ }^{57}$ J. Derrida, Espectros de Marx, cit., p. 100.

${ }^{58}$ J. Derrida, Fuerza de ley. El "Fundamento místico de la autoridad", cit., p. 23.

${ }^{59}$ Gianni Vattimo realiza un excelente análisis del mesianismo derridiano a partir de su vínculo con la historia. Por un lado, afirma que en Derrida no hay una historia de su pensamiento, entendida como evolución o desarrollo continuo, ya que rechaza la Historia en tanto transformación lineal. Sin embargo, la deconstrucción depende siempre de hechos históricos determinados. Por otro lado, la herencia mesiánica del trabajo de Derrida lo acercaría peligrosamente a lo que algunos llaman su lado existencialista. Si la diferencia no tiene historia, puede convertirse en una archi-estructura que hará de cualquier otro un testimonio de la misma, formalizándolo y quitándole su singularidad en tanto acontecimiento. Así, para Vattimo la tarea de Derrida será pensar en la alteridad en términos concretamente históricos para así evitar caer en la metafísica. G. Vattimo, "Historicidad y diferencia. En torno al mesianismo de Jacques Derrida", trad. M. A. Quintana Paz, en Solar 2, 2006, pp. 123-127.
} 
cución ${ }^{60}$ y cuya máxima expresión es la democracia por venir. Ésta es un llamado a volver la filosofía sobre la actualidad, y tal vez sea por ello que el pensamiento de Derrida esté vigente en el así llamado comunitarismo impolítico, bajo el que suscribimos a filósofos como Nancy, Esposito y Agamben, entre otros, que están actualmente pensando lo político en el mundo de hoy ${ }^{61}$.

\footnotetext{
60 "Una estructura inmanente de promesa o deseo, una espera sin horizonte de espera informa toda palabra." J. Derrida, El monolingüismo del otro o la prótesis del origen, trad. H. Pons, Bs. As., Manantial, 1997, p. 36.

${ }^{61}$ En varios pasajes de su obra Derrida reflexiona sobre la relación entre los intelectuales y el presente. Entre otros remitimos a J. Derrida, "Hoy en día", en No escribo sin luz artificial, trad. R. Ibañez y M. J. Pozo, Valladolid, Cuatro ediciones, 1999; “<Pero..., no, pero..., nunca..., y sin embargo..., en lo que se refiere a los media> (Los intelectuales. Tentativa de definición por sí mismos. Encuesta)", en Papel máquina, trad. C. de Peretti y P. Vidarte, Madrid, Trotta, 2003, 199-208; y “¿Qué hacer de la pregunta < ¿Qué hacer?>?”, trad. B. Mazzoldi, en El tiempo de una tesis. Desconstrucción e implicaciones conceptuales, Barcelona, Proyecto A Ediciones, 1997, pp. 29-39.
} 